\title{
Palaeontology under a Himalayan shadow
}

CHANDIGARH is the northern city now belonging to no state of India, but instead sandwiched between the Punjab and Haryana, respectively Sikh and Hindu predominantly. It is also the city that the French architect Le Corbusier sought in the 1930 s to turn into an architectural paradise with several striking buildings; although they have not weathered well, their presence seems to have given the city as a whole an architectural selfconsciousness not apparent elsewhere.

But Chandigarh is also the home of $\mathrm{V}$. J. Gupta, professor of palaeontology in the department of geology at the Panjab University of Chandigarh. Gupta is now best known not for the significance of his Himalyan fossil finds, but for the allegation (see J. A. Talent, Nature 338, $613 ; 1989$ ) that many of his fossils, described in more than 200 publications, do not derive from the Himalayas but from where in the world, often the palaeontological collections of university departments that Gupta had visited on his travels.

What follows is an account of a conversation with Gupta, as well as with others at the university concerned in the affair. It is proving to be a protracted business. Talent's accusations that Gupta had systematically salted Himalayan rocks with specimens from where are now six years old. Since then, the accusations have been endorsed by two independent investigations - by the Indian Geological Survey and by an expedition to the supposed sites of the fossil finds under the leadership of Dr A. S. Paintal. Gupta was at first suspended from the university, but then reinstated. For the past two and a half years, he and others have been giving evidence at an enquiry conducted by a retired judge, $\mathbf{M}$. S. Gujrat, which is now in its closing stages. There should be a judgement during 1994.

Since Talent's article appeared, there has been some concern that some of Gupta's associates at Chandigarh, notably Dr A. D. Ahluwalia and Professor S. B. Bhatia, appeared over-splenetic in their denunciation of Gupta, with whom they had jointly published articles. A conversation over lunch in Chandigarh made it crystal clear that each has been deeply wronged by Gupta. Bhatia, being the older, is the more philosophical.

To the complaint of colleagues in the geology department that they were happy enough to go along with Gupta while he was able to publish articles with their names included, and that they have turned against him to save their own skins as potentially culpable co-authors, they reply that they have no choice. Bhatia is nearing retirement while Ahluwalia, who does not think he could easily find a comparable job elsewhere, is fighting for his livelihood.

V. J. Gupta himself is more urbane. On the telephone when agreeing to this interview, he had explained that he would probably not be able to discuss the details of the case because there is a judicial inquiry going on. In the event, in the comfort of his house in a row of three, at the bottom of the campus and armed with a stack of papers by his side, he was more than ready to discuss the details of the case.

Why had Nature published Talent's accusations without letting him, Gupta, see them in advance? Was not this or that accusation, that he could not have visited some of the sites recorded in the published papers, contradicted by this piece of paper in his hand consisting of a laisser-passer from the military authorities for the locality concerned? (One of the difficulties is that many of the Gupta sites are in India's disputed border regions with China.)

For fear that this kind of argument would easily occupy the available hour, it seemed best to get down to basics. So is it not the case that the judicial inquiry, whatever its outcome, is irrelevant to his reputation in the scientific community? Is it not the case that the scientific community believes Talent, not Gupta? Did Gupta believe he could rehabilitate his reputation in the face of general disbelief?

Disarmingly, Gupta agreed that his reputation is in tatters. Implying confidence that he would be exonerated by the investigation under way, he also acknowledged that it would be difficult to win back his reputation among palaeontologists even when the inquiry was complete. But he would do whatever was necessary.

What about giving people elsewhere full access to his fossil specimens? Even though they are mostly microscopic entities, it might just be possible to identify some features of the rock in which they had originally been embedded?

Gupta's reply to that was breathtaking. "But I have some specimens of rock that have not been ground up. I've not told people about this. I've kept them to myself." The surprise in that, of course, is that one such as Gupta now exposed to the third inquiry into his integrity as a scientist should have neglected to disclose to any of them evidence that could well establish his innocence of the charges against him. That he should have retained some unprocessed rock is natural, but that he should not have used it in his defence is mystifying.

In an isolated city a long way north of
Delhi, it is tempting to sympathize with the co-authors' alarm. Will it be, a few months from now, that the remaining rock will be ground up, found innocent of fossils (conodonts in particular) and the coauthors then accused of having spiked the original samples with material from elsewhere than the Himalyas?

Later that same evening, it emerged from a conversation with $\mathrm{Dr} R$. P. Bambah, vice-chancellor at Chandigarh until mid-1992, that there are other more mundane complications. One of them concerns the status of Indian academics, which is that of government employees, who cannot be deprived of the privileges of the posts to which they have been appointed without prescribed due process. Bambah says that, without an independent quasijudicial inquiry in the form that he established, any move against Gupta parmanently to attenuate his academic privileges would have been overturned by the courts.

Back in Delhi, Paintal seems to fluctuate between annoyance and resignation, impatient of the legal niceties of the Gupta case. But his report (supplied by another source) is not quite the weighty document the circumstances would seem to require, consisting of a one and a half page covering letter enclosing laboratory notes of investigations by specialists on the expedition to Spiti, in the Himalayas.

The practical consequences for Chandigarh of the Gupta affair are so far two. First, the University Grants Commission has deprived the geology department of its special status, which those opposed to Gupta say has hurt only the students there, while the geology department seems to spend its non-teaching time mulling over the details of this murky affair. Personal animosity (on both sides) is palpable.

Whatever the outcome of the judicial enquiry, it will be irrelevant outside Chandigarh. Gupta's confidence that he can rehabilitate his reputation betokens, at best, a failure to appreciate the seriousness of the misdemeanours embodied in the documentary evidence in the literature, at worst a belief that the research community's attention span is short.

In Chandigarh, the verdict will matter a great deal. The atmosphere in the geology department is poisoned. Honest coauthors have been castigated for not having complained earlier, and then their complaints have been described as attempts to save their own skins. But if the enquiry finds no charges proved, Gupta will be next-but-one in line to be Dean. The university cannot afford to wait for the judicial enquiry to end before tackling those problems. 